\title{
GEOMETRY AND GÂTEAUX SMOOTHNESS IN SEPARABLE BANACH SPACES
}

\author{
P. HÁJEK, V. MONTESinOS AND V. ZIZLER
}

\begin{abstract}
It is a classical fact, due to Day, that every separable Banach space admits an equivalent Gâteaux smooth renorming. In fact, it admits an equivalent uniformly Gâteaux smooth norm, as was shown later by Day, James, Swaminathan, and independently by the third named author. It is therefore rather unexpected that the existence of Gâteaux smooth renormings satisfying various quantitative estimates on the directional derivative has rather strong structural and geometrical implications for the space. For example, by a result of Vanderwerff, if the directional derivatives satisfy a $p$-estimate, where $p$ varies arbitrarily with respect to the point and the direction in question, then the Banach space must be an Asplund space. In the present survey paper, we discuss the interplay between various types of Gâteaux differentiability of norms and extreme points with the geometry of separable Banach spaces. In particular, we present various characterizations of Asplund, reflexive, superreflexive, and other classes of separable Banach spaces, via smooth as well as rotund renormings. We also include open problems of various levels of difficulty, which may foster research in the area of smoothness and renormings of Banach spaces.
\end{abstract}

Mathematics subject classification (2010): 46B03, 46B10.

Keywords and phrases: Gâteaux differentiable norms; extreme points; Radon-Nikodým property; superreflexive spaces; Hilbertian spaces.

\section{REFERENCES}

[1] F. Albiac and N. Kalton, Topics in Banach spaces, Graduate Texts in Mathematics, SpringerVerlag, 2006.

[2] M. BAChir And A. Danillidis, A dual characterisation of the Radon-Nikodým property, Bull. Austral. Math. Soc. 62 (2000), 379-387.

[3] J. BORWEIN AND M. FABIAN, On convex functions having points of Gâteaux differentiability which are not points of Fréchet differentiability, Canadian J. Math. 45, 6 (1993), 1121-1134.

[4] J. Borwein And D. NolL, Second order differentiability of convex functions: A.D. Alexandrov's theorem in Hilbert space, Trans. Amer. Math. Soc. 342 (1994), 43-81.

[5] J. Borwein And J. VAnderwerfF, Convex Functions; Constructions, Characterizations and Counterexamples, Cambridge University Press, 2010.

[6] J. BorWein, J. GILES AND J. VANDERWERFF, Rotund norms, Clarke subdifferentials and extensions of Lipschitz functions, Nonlinear Analysis 48 (2002), 287-301.

[7] J. Bourgain, A geometric characterization of the RNP in Banach spaces, Compositio Math. 36 (1978), 3-6.

[8] J. Bourgain, La propriété de Radon-Nikodým, Publ. Math. Univ. Pierre et Marie Curie 36 (1979).

[9] J. Bourgain, Dentability and finite-dimensional decompositions, Studia Math. 67 (1980), 135-148.

[10] J. Bourgain And H. Rosenthal, Geometrical implications of certain finite dimensional decompositions, Bull. Soc. Math.Belg. 32 (1980), 57-82.

[11] J. Bourgain And H. P. Rosenthal, Martingales valued in certain subspaces of $L_{1}$, Israel J. Math. 37 (1980), 54-75.

[12] J. Bourgin, Geometric Aspects of Convex Sets with the Radon-Nikodym Property, Lecture Notes in Mathematics 993, Springer-Verlag, Berlin, Heidelberg, New York, 1983. 
[13] J. B. Collier, The dual of a space with the Radon-Nikodym property, Pacific J. Math. 64 (1976), 103-106.

[14] D.F. Cudia, The geometry of Banach spaces. Smoothness, Trans. AMS 110 (1964), 284-314.

[15] M. M. DAY, Normed Linear Spaces, 3rd Edition, Springer-Verlag, New York, 1973.

[16] M. M. DaY, Uniform convexity III, Bull. Amer. Math. Soc. 49 (1943), 745-750.

[17] R. Deville, G. Godefroy, D. E. G. Hare, AND V. ZIZler, Differentiability of convex functions and the convex point of continuity property in Banach spaces, Israel J. Math. 59, 2 (1987), 245-255.

[18] R. Deville, G. Godefroy, ANd V. Zizler, Smooth bump functions and geometry of Banach spaces, Mathematika 40 (1993), 305-321.

[19] R. Deville, G. Godefroy, And V. Zizler, Smoothness and Renormings in Banach Spaces, Pitman Monographs and Surveys in Pure and Applied Mathematics 64, 1993.

[20] R. Deville, R. GonZalo, and J. Jaramillo, Renormings of $L_{p}\left(L_{q}\right)$, Math. Proc. Cambridge Philos. Soc. 126 (1999), 155-169.

[21] J. Diestel, Sequences and Series in Banach spaces, Graduate Texts in Mathematics 92, SpringerVerlag, New York, 1984.

[22] J. DixmieR, Sur un théorème de Banach, Duke Math. J. 15 (1948), 1057-1071.

[23] G. A. Edgar And R. H. WheEler, Topological properties of Banach spaces, Pacific J. Math. 46 (1984), 317-350.

[24] P. ENFLO, Banach spaces which can be given an equivalent uniformly convex norm, Israel J. Math. 13 (1972), 281-288.

[25] M. Fabian, Differentiability of Convex Functions and Topology-Weak Asplund Spaces, John Wiley and Sons, 1997.

[26] M. Fabian, G. Godefroy And V. ZIZler, The structure of uniformly Gâteaux smooth Banach spaces, Israel J. Math. 124 (2001), 243-252.

[27] M. Fabian, J. J. M. Whitfield, V. ZIZler, Norms with locally Lipschitzian derivatives, Israel J. Math. 44 (1983), 262-276.

[28] M. Fabian, P. Habala, P. Hájek, V. Montesinos, J. Pelant, and V. Zizler, Functional Analysis and Infinite-dimensional Geometry, CMS Books in Mathematics, Springer-Verlag, 2001.

[29] M. Fabian, P. Habala, P. HáJeK, V. Montesinos, And V. Zizler, Banach Space Theory: The Basis for Linear and Nonlinear Analysis, CMS Books in Mathematics, Springer-Verlag, 2011.

[30] N. Ghoussoub, B. Maurey AND W. Schachermayer, Geometrical implications of certain finite dimensional decompositions, Trans. Amer. Math. Soc. 117 (1990), 541-584.

[31] J. R. GILES, A nonreflexive Banach space has nonsmooth third conjugate space, Canad. Math. Bull. 17 (1974), 117-119.

[32] J. R. GILES, A subdifferential characterisation of Banach spaces with the Radon-Nikodým property, Bull. Austral. Math. Soc. 66 (2002), 313-316.

[33] G. Godefroy, Renormings of Banach spaces, in Handbook of Banach spaces I, Editors W. B. Johnson and J. Lindenstrauss, Elsevier, 2001, 781-835.

[34] B. V. Godun, Preserved extreme points, Functional Anal. i prilozhen 19 (1985), 75-76.

[35] B. V. Godun, Points of smoothness of convex bodies in separable Banach spaces, Matem. Zametki 38 (1985), 713-716.

[36] J. Hagler, A counterexample to several questions about Banach spaces, Studia Math. 60 (1977), 289-308.

[37] P. HÁJeK, Dual renormings of Banach spaces, Comment. Math. Univ. Carol. 37 (1996), 241-253.

[38] P. Hájek, V. Montesinos, J. VanderwerfF, V. Zizler, Biorthogonal Systems in Banach Spaces, CMS Series, Springer, New York, 2008.

[39] P. HÁJeK And M. Johanis, A renorming characterization of reflexivity, J. Funct. Anal. 211 (2004), $163-172$.

[40] P. HÁJEK And J. RYChTÁř́, Renorming the James tree space, Trans. AMS. 257, 9 (2005), 37753788.

[41] R. E. HufF AND P. D. Morris, Dual spaces with the Krein Milman property have the Radon Nikodým property, Proc. Amer. Math. Soc. 49 (1975), 104-108.

[42] W.B. Johnson And J. Lindenstrauss (EDS.), Handbook of the Geometry of Banach Spaces, Vol. 1, Elsevier, 2001.

[43] V. KLEE, Some new results on smoothness and rotundity in normed linear spaces, Math. Annalen 139 (1959), 51-63. 
[44] B. L. Lin, P. K. Lin, AND S. TroyAns KI, A characterization of denting points of a closed, bounded, convex set, Longhorn Notes, U. T. Functional Analysis Seminar, 1985-1986. The University of Texas at Austin, pp. 99-101.

[45] B. L. Lin, P. K. Lin, S. Troyanski, Characterizations of denting points, Proc. Amer. Math. Soc. 102 (1988), 526-528.

[46] J. LindenstrauSS AND C. STEGALl, Examples of separable spaces which do not contain $\ell_{1}$ and whose duals are nonseparable, Studia Math. 54 (1975), 81-105.

[47] E. MatoušKová, Concerning weak* ${ }^{*}$-extreme points, Comment. Math. Univ. Carolinae 36, 2 (1995), 245-248.

[48] S. MazuR, Uber Schwache Konvergenz in den Raumen $\left(L_{p}\right)$, Studia Math. 4 (1933), $128-133$.

[49] D. Mclaughlin, R. Poliquin, J. VanderwerfF, And V. Zizler, Second-order Gâteaux differentiable bump functions and approximations in Banach spaces, Can. J. Math.Vol. 45, 3 (1993), $612-625$.

[50] D. Maclaughlin And J. VAnderwerfF, Higher order Gateaux smooth bump functions on Banach spaces, Bull. Austral. Math. Soc. 51 (1995), 291-300.

[51] V.D. Milman, Geometric theory of Banach spaces. II: Geometry of the unit sphere, Russ. Math. Surv. 26 (1972), 79-163.

[52] P. D. Morris, Disappearance of extreme points, Proc. Amer. Math. Soc. 88 (1983), 244-246.

[53] E. Odell AND TH. SCHLuMPRECHT, Asymptotic properties of Banach spaces under renormings, Journal AMS 11 (1998), 175-188.

[54] R. R. Phelps, A representation theorem for bounded convex sets, Proc. Amer. Math. Soc. 11 (1960), 976-983.

[55] R. R. Phelps, Convex Functions, Monotone Operators and Differentiability, Lecture Notes in Mathematics 1364, Springer-Verlag, 1993.

[56] G. PISIER, Martingales with values in uniformly convex spaces, Israel J. Math. 20 (1975), 326-350.

[57] J. RAINWATER, A nonreflexive Banach space has nonsmooth third conjugate space, unpublished manuscript.

[58] W. SCHACHERMAYER, The Radon-Nikodým and Krein-Milman properties are equivalent for strongly regular sets, Trans. Amer. Math. Soc. 303 (1987), 673-687.

[59] W. Schachermayer, A. Sersouri, And E. Werner, Moduli of non-dentability and the RadonNikodym property in Banach spaces, Israel J. Math. 65 (1989), 225-257.

[60] I. SINGER, On the problem of non-smoothness of non-reflexive second conjugate space, Bull. Austral. Math. Soc. 12 (1975), 404-416.

[61] M. Smith, Rotundity and smoothness in conjugate spaces, Proc. Amer. Math. Soc. 61, 2 (1976), 232-234.

[62] C. Stegall, The Radon Nikodým property in conjugate spaces, Trans. Amer. Math. Soc. 206 (1975), 213-223.

[63] C. StegalL, Vorlesungen aus dem Fachbereich Mathematik der Universität Essen, Heft 10, 1983, $1-61$.

[64] F. Sullivan, Geometrical properties determined by the higher duals of a Banach space, Illinois J. Math. 21 (1977), 315-331.

[65] M. Talagrand, Sur la propriete de Radon Nikodym dans les espaces de Banach reticulés, C. R. Acad. Sci. Paris 288, ser. A (1979), 907-810.

[66] WeE-KeE TAng, A note on preserved smoothness, Serdica Math. J. 22 (1996), 29-32.

[67] N. TOMCZAK-JAEGERMANN, The moduli of smoothness and convexity and the Rademacher averages of trace classes $S_{p}, 1<p<\infty$, Studia Math. 50 (1974), 163-182.

[68] S. TROYAnsKi, An example of a smooth space, the dual of which is not strictly convex, (Russian) Studia Math. 35 (1970), 305-309.

[69] S. TROYANS KI, On locally uniformly convex and differentiable norms in certain nonseparable Banach spaces, Studia Math. 37 (1971), 125-138.

[70] S. Troyanski, Gâteaux differentiable norms in $L_{p}$, Math. Ann. 287 (1990), 221-227.

[71] J. VANDERWERFF, Second-order Gâteaux differentiability and an isomorphic characterization of Hilbert spaces, Quart. J. Math. Oxford 44 (1993), 249-255.

[72] A. Zygmund, Trigonometric Series, Vol. I, Cambridge University Press, 1959. 